\title{
A Low Cost Broadband Planar Antenna
}

\author{
R. Dakir, J. Zbitou, A. Mouhsen, A.Tribak, Angel Mediavilla Sanchez, and M. Latrach
}

\begin{abstract}
This paper comes with a new low cost compact planar antenna with the improvement of the bandwidth. This structure is based on an FR4 substrate. To develop this structure we have conducted many optimizations by using Momentum integrated into ADS “Advanced Design System" from Agilent Technologies and compared with CST Microwave studio. The comparison between simulation and measurement results permits to validate the final achieved antenna structure with an improvement of the bandwidth. The antenna achieved is a low cost planar, simple in structure and easy to be fabricated, thus promising for applications in wireless communication systems.
\end{abstract}

Index Terms - Bandwidth improvement, microstrip antennas, wide band antennas.

\section{INTRODUCTION}

In recent years, the technologies of wireless communication systems have been rapidly increasing the demands for greater capacities broadband service to support wireless communication, especially for applications of multimedia communications (data, voice, pictures, and video) and wireless radio technologies (Bluetooth, Wifi, GPRS, UMTS, Wimax). They have a great success. As well, the applications require high bandwidth between the mobile communication equipments with reduced size.

Therefore, to meet the increased demand for wireless communication with high bandwidth, the future generations of equipments will need to integrate with antennas systems to provide high performance and to fulfill the needs in terms of gain, bandwidth, etc. Those antennas should function over multi-frequency bands or over wideband. They should be compact and easy to be integrated into the radio systems, which require innovation of new antenna structure with low cost of manufacturing; and they don't have any electromagnetic compatibility problems with the surrounding electronic environment. The antennas adapted for this kind applications are the microstrip printed antennas which allow the development of miniature compact antennas' structure. But this technology generates disadvantages which have low gain, and it supports a low power level.

So, in order to design miniature printed antennas with high bandwidth, many techniques for improving the operating

Manuscript received February 2013; revised April 11, 2013.

R. Dakir is with the FST university Hassan 1st Settat Morocco (e-mail: dakir_fsts@hotmail.com).

J. Zbitou was with the Electronics in FPK university Hassan $1^{\text {st }}$ Settat Morocco.

A. Mouhsen is with the Electronics in FSTS university Hassan $1^{\text {st }}$ Settat Morocco.

Angel Mediavilla Sanchez is with the National Institute of Post and Telecommunication, Rabat, Morocco.

M. Latrach is with the microwave engineering with the Ecole Suprieure d'Electronique de l'Ouest (ESEO), Angers, France. bandwidth have been studied [1]-[7]. This work presents a new low cost compact antenna structure with the improvement of the bandwidth. The type of the chosen port for feeding the antenna is coplanar and easy to be integrated with passive or active elements.

\section{THE CONCEPTION OF A PRINTED BROADBAND}

A variety of broadband techniques have been developed by using some factors which affect the bandwidth of a microstrip patch antenna likethe shape of the radiator, the feeding scheme, the substrate and the arrangements of radiating and parasitic elements. In our study, the goal is to improve the bandwidth of the rectangular antenna, by using the slot technique. To do that and validate the antenna structure, we have manipulated Momentum electromagnetic software integrated into ADS "Advanced Design System" from Agilent Technologies. This program is recommended for planar antenna structure with weak thickness of the substrate. The substrate used for this design is FR4 with the following characteristics:

- Relative dielectric permittivity $\varepsilon_{r}=4.3$.

- Substrate thickness: $h=1.6 \mathrm{~mm}$.

- Dielectric loss: $\tan (\delta)=10^{-3}$

- Metallic thickness: $t=35 \mu \mathrm{m}$.

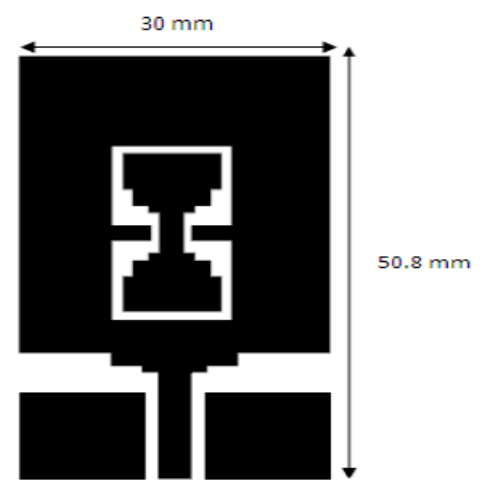

Fig. 2. The structure of the optimized broadband antenna.

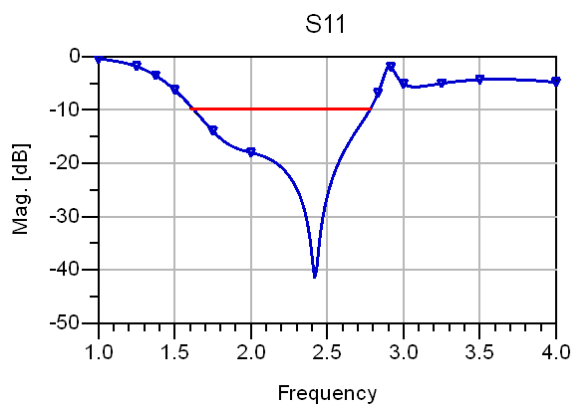

Fig. 3. Simulated return loss versus frequency in GHz.

For optimizing the antenna structure and increasing the bandwidth we have used the optimization technique 
integrated in ADS which allows us to validate the structure presented in Fig. 2.

As shown in Fig. 3, the matching input impedance is achieved along a frequency band between $1.7 \mathrm{GHz}$ and 2.8 $\mathrm{GHz}$ with return loss below-10dB.

Before achieving the antenna and for comparison we have done another simulation by using CST Microwave Studio for 3D electromagnetic simulation.

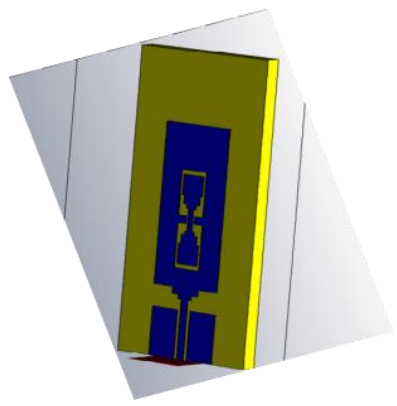

Fig. 4. The antenna structure in 3D.

As illustrated in Fig. 5, we conclude that we have approximately the same result as with ADS.

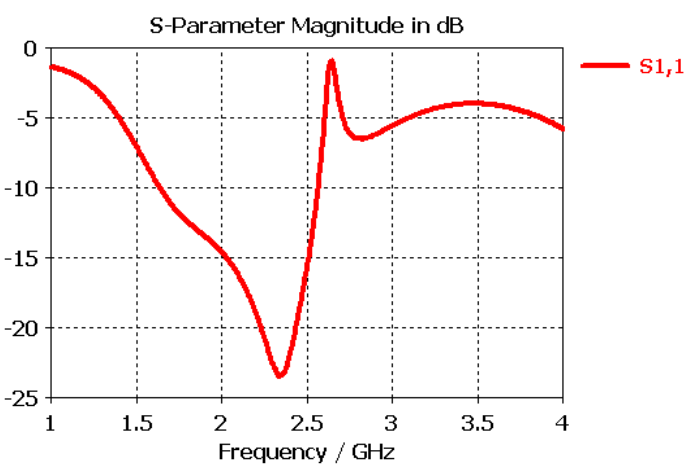

Fig. 5. Simulated return loss versus frequency.

As an example, we have the radiation pattern presented in Fig. 6 at $2 \mathrm{GHz}$.

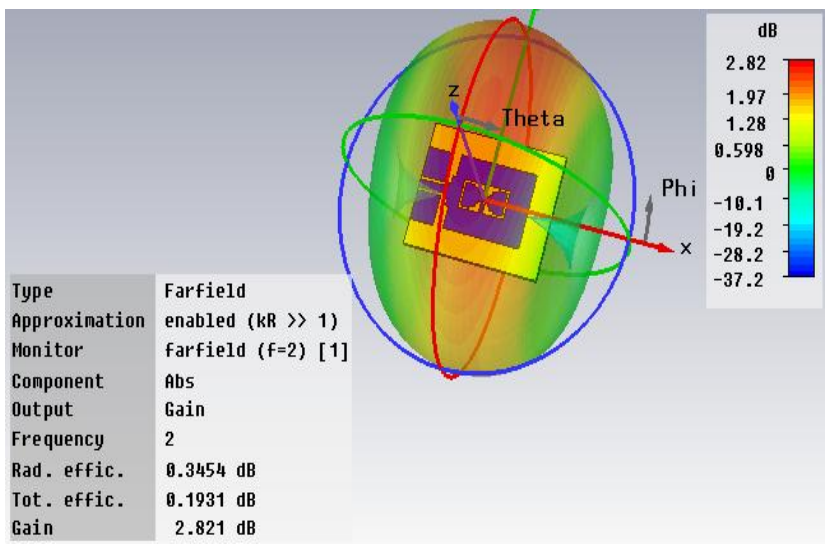

Fig.6.3D radiation pattern @ 2 GHz.

\section{ACHIEVEMENT AND MEASUREMENT}

\section{A. Achievement and Calibration}

After the comparison of simulation results on ADS and CST, we have achieved the structure antenna by using the LPKF machine.

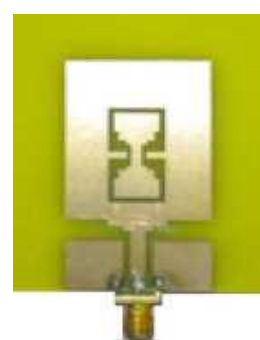

Fig. 7. Photograph of the fabricated structure with LPKF machine.

The kit of calibration used in the setup test is $3.5 \mathrm{~mm}$, associated to a VNA R\&S@ZVB20 from Rohde \& Schwarz. The test has taken into account the return losses in the transitions.

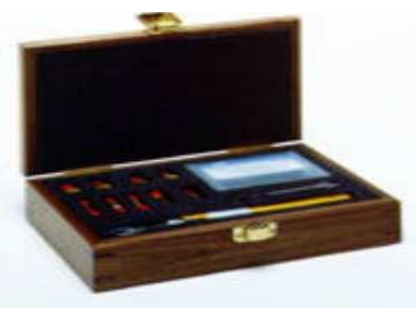

Fig. 8 Calibration Kit $3.5 \mathrm{~mm}$

\section{B. Test and Comparison}

After series of test, we have done a comparison between simulation on ADS, CST and measurement results as shown in the following figures.

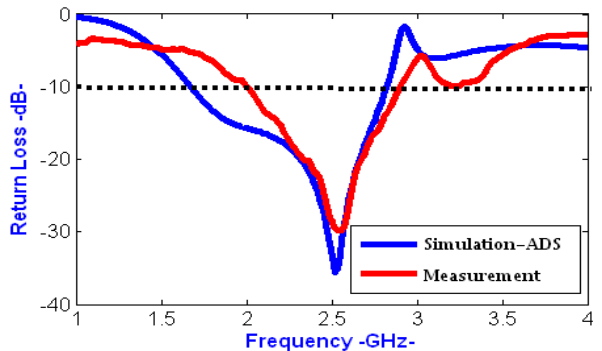

(a)

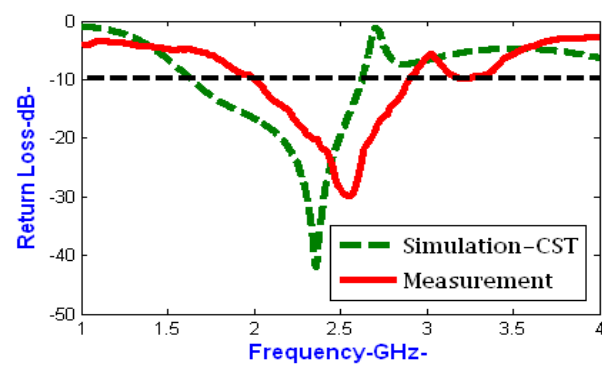

(b)

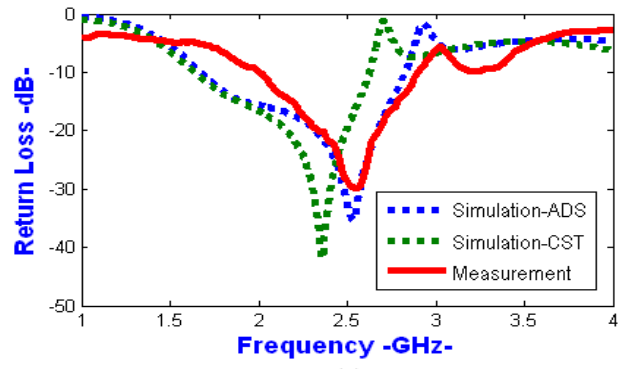

(c)

Fig. 9. Comparison of simulated and measured return loss. 
We conclude that we have an agreement between simulation and measurements results. We note that the simulation results on ADS are the closest to the measured results. This allows the validation of the antenna structure with large frequency band ranging from $2.1 \mathrm{GHz}$ to $2.8 \mathrm{GHz}$, with a bandwidth of $700 \mathrm{MHz}$, compared to the narrow band of a classic rectangular patch antenna. For the measured radiation pattern at $2 \mathrm{GHz}$, it's presented in Fig. 10 for $\mathrm{E}$ and H plane.

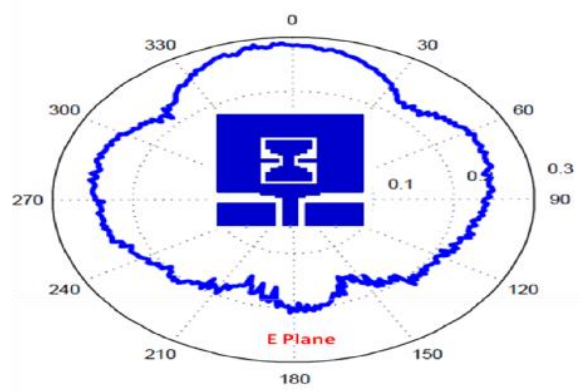

(a)

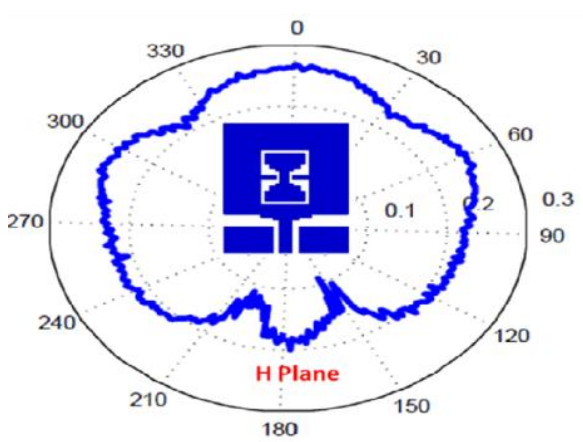

(b)

Fig. 10. Radiation pattern at $2 \mathrm{GHz}$ for $\mathrm{E}$ and $\mathrm{H}$ plane.

\section{CONCLUSION}

This work has presented a study on a new low cost planar broadband antenna structure. The measurement and simulation results are in agreement which validate the antenna structure with a bandwidth of $700 \mathrm{MHz}$. This antenna is feed with CPW line which permits to associate it with printed circuits board. To improve the bandwidth of the antenna we have used a simple technique based on the use of slot technique.

\section{ACKNOWLEDGMENT}

We thank Mr. Angel Mediavilla Sanchez Director of DICOM Laboratory in Santander in Spain and Mr. Mohamed Latrach Professor in ESEO France, for allowing us to use and to perform simulations by using softwares and measurement on the VNA and anechoic chamber.

\section{REFERENCES}

[1] A. F. Sun, Y. Z. Yin, S. H. Jing, and M. Abri, "BroadBand CPW-Fed Antenna with Band-Rejected Characteristic for Wlan-Wimax Operation," Progress in Electromagnetics Research C China, vol. 22, pp. 47-54, 2011.

[2] W. Liao and Q. W. Chu, "CPW-Fed square slot antenna with lightening-shaped feedline for broadband circulary polarized radiation," China, vol. 18, pp. 61-69, 2010
[3] M. T. Islam, M. N. Shakib, N. Misran, and T. S. Sun, "Broadband microstrip patch antenna," European Journal of Scientific Research, vol. 27 , no. 2, pp. 174-180, 2009.

[4] M. A. Saed, "Reconfigurable broadband microstrip antenna fed by a coplanar waveguide," PIER, vol. 55, pp. 227-239, 2005.

[5] Q. Chen, H. L. Zengh, T. Quan, and X. Li, "Broadband CPX-Feed circulary polarized antenna with equiangular tapered-shaped feedline for ultra-wideband applications," vol. 26, pp. 83-95, 2012.

[6] P. J. Soh and A. E. Guy, "Evaluation of flexible CPW-Fed ultra wide-band textile antennas," in Proc. 2011 IEEE International FR and Microwave Conference (RFM 2011), Malaysia, vol. 60, pp. 58-62.

[7] L. Guo, S. Wang, X. Chen, and C. G. Parini, "Study of a compact antenna for UWB applications," IET Electronic Letters, vol. 46, no. 2 , January 21st, 2010, pp. 115-116

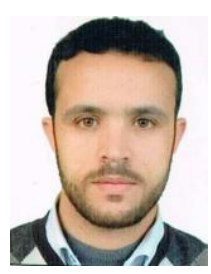

R. Dakir was born on 16 February 1982. He received the Master degree in science of computer and systems from the FST University of Hassan $1^{\text {st }}$ in Settat Morocco. He is currently a Phd student in FST university Hassan $1^{\text {st }}$ Settat Morocco. He is involved in the design of microwave hybrid circuits and antennas.

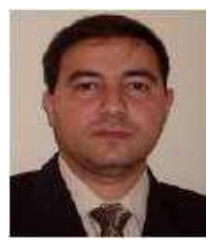

J. Zbitou was born in Fes, Morocco, in June1976. He received the $\mathrm{Ph} . \mathrm{D}$. degree in electronics from the University of Nantes, Nantes, France, in 2005. He is currently a Professor of Electronics in FPK university Hassan 1 Settat Morocco. He is involved in the design of hybrid, monolithic active, and passive microwave electronic circuits

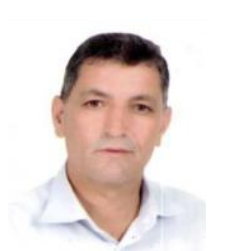

A. Mouhsen was born in May 1960. He received the $\mathrm{Ph} . \mathrm{D}$. degree in electronics from the University of Bordeaux I, France. He is currently a Professor of Electronics in FSTS university Hassan $1^{\text {st }}$ Settat Morocco. He is involved in the design of hybrid, active, and passive microwave electronic circuits and digital systems.

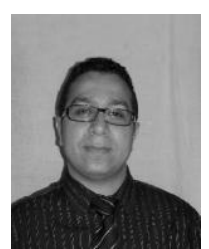

A. Tribak was born in Larache, Morocco, in 1981. He received the M.Sc. degree in physics from Abdelmalek Essaadi University, Tétouan, Morocco, in 2006. He received a Master degree in communications engineering from the University of Cantabria, Santander, Spain, in 2008, and received the $\mathrm{PhD}$ of Telecommunication degree in 2011, from the University of Cantabria Santander, Spain. Since 2006 to 2011, he has been with the Department of Communications Engineering, University of Cantabria Since 2011 he is a Professor in the National Institute of Post and Telecommunication, Rabat, Morocco. His main areas of activities are microwave circuits and systems; antenna feed subsystems for satellite and radio-astronomy applications.

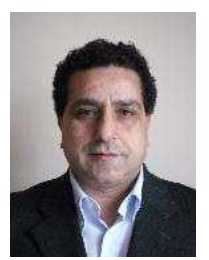

M. Latrach was born in Douar Ksiba, Sless, Morocco, in 1958. He received the $\mathrm{Ph} . \mathrm{D}$. degree in electronics from the University of Limoges, Limoges, France, in 1990. He is currently a Professor of microwave engineering with the Ecole Suprieure d'Electronique de l'Ouest (ESEO), Angers, France, where his research involves RF and microwaves. His field of interest is the design of hybrid, monolithic active, and passive microwave circuits, materials, LH materials, antennas and their applications in wireless communications, and wireless power transmission. 